ISSN 1984-3534

\title{
SEGURANÇA PÚBLICA: CLASSIFICAÇÃO DAS CIDADES DA PARAÍBA QUANTO A PROPENSÃO A CRIMINALIDADE ${ }^{1}$
}

\author{
Bárbara Lopes de Oliveira ${ }^{a}$, Maria Creuza Borges de Araújo ${ }^{a^{*}}$ \\ ${ }^{\mathrm{a}}$ Centro de Desenvolvimento Sustentável do Semiárido \\ Universidade Federal de Campina Grande - UFCG, Sumé-PB, Brasil
}

Recebido 26/03/2020, aceito 27/08/2020

\begin{abstract}
RESUMO
O intenso e recorrente debate acerca da insegurança mostra que este é um temor constante em todas as regiões do Brasil. Assim, é necessário que os governantes busquem formas adequadas de reduzir a criminalidade em todo o território nacional. Neste sentido, este artigo propõe um modelo multicritério para a classificação de municípios quanto à criminalidade, considerando fatores demográficos e sociais, com o intuito de propor políticas adequadas para localidades com diferentes níveis de propensão à criminalidade. $\mathrm{O}$ modelo foi aplicado nos municípios do Estado da Paraíba, e demonstrou que grande parcela destes possui uma alta propensão à ocorrência de crimes. Posteriormente, foram sugeridas ações para reduzir esses índices, priorizando as cidades em situação crítica. A sistemática apresentou como principais vantagens: procedimento estruturado para a resolução do problema, priorização de locais com maior propensão à criminalidade quanto à implantação de políticas públicas, e análise da situação do Estado quanto à ocorrência de crimes.
\end{abstract}

Palavras-chave: Segurança pública, Apoio multicritério a decisão, Municípios.

\begin{abstract}
The intense and recurring debate about insecurity shows that this is a constant fear in all regions of Brazil. Thus, government officials must seek appropriate ways to reduce crime throughout the national territory. In this sense, this work proposes a multicriteria model for the classification of municipalities regarding crime, considering demographic and social factors, to propose appropriate policies for locations with different levels of criminal propensity. The model was applied in the municipalities of the State of Paraíba and demonstrated that a large portion of these has a high propensity for the occurrence of crimes. Subsequently, actions were suggested to reduce these rates, giving priority to cities in critical situations. The systematic presented as main advantages: structured procedure for the resolution of the problem, prioritization of places with a greater propensity to criminality regarding the implementation of public policies and analysis of the State's situation regarding crime.
\end{abstract}

Keywords: Public security, Multicriteria decision aid, Cities.

*Autor para correspondência. E-mail: maria.creuza@ufcg.edu.br

DOI: 10.4322/PODes.2020.004

${ }^{I}$ Todos os autores assumem a responsabilidade pelo conteúdo do artigo. 


\section{Introdução}

No Brasil, a violência é um fenômeno comportamental complexo de agressividade, que envolve as bases históricas do país e atinge todas as camadas da sociedade. Figueiredo (2013) observa que essa questão é discutida intensamente tanto em meios de comunicação de massa como em ambientes interpessoais, sendo um receio para a maioria dos cidadãos, visto o medo de ser mais uma vítima da violência. Neste sentido, Fajnzylber et al. (2000) afirmam que a insegurança passou a ser uma questão tão alarmante que as pessoas tratam o assunto com maior grau de atenção do que aqueles relacionados à economia, o que é justificado pelo efeito negativo que o aumento da criminalidade pode exercer para a qualidade de vida da sociedade.

Embora as leis vigentes busquem garantir a segurança à toda a população, no Brasil este problema transcende o cenário de combate à criminalidade. Então, é necessário que os governantes adotem medidas de longo prazo relacionadas a políticas de segurança integradas a outras políticas, dada a inter-relação entre criminalidade e fatores sociais, estruturais e econômicos (Anjos et al., 2017). Diante disso, o problema de segurança pública sempre esteve em ênfase, e muito se fala sobre como as medidas adotadas para garanti-la a população são ineficazes no âmbito nacional, estadual e municipal.

Com relação ao Estado da Paraíba, Nunes (2019) aborda que a taxa de crescimento dos índices de violência começou a decrescer a partir de 2011, com cinco anos de reduções consecutivas. O autor acrescenta que o Estado chegou, em 2016, a uma redução de $12 \%$ e uma taxa de 33,1 homicídios por cada grupo de 100 mil habitantes. Ainda assim, de acordo com o IPEA (2017), por mais que o programa Paraíba pela Paz tenha alcançado um bom desenvolvimento e freado as altas taxas de crimes do Estado, o Governo precisa aprimorar ainda mais seus planos e estratégias com relação à segurança, implantando ações de forma mais efetiva e eficiente, alcançando todos os âmbitos caracterizados como violência.

Neste sentido, é importante entender esta questão de maneira ampla e deve-se considerar vários critérios para a avaliação dos índices de propensão a criminalidade. Desta forma, esta pesquisa tem como objetivo verificar e estudar os indicadores que influenciam a violência nas diferentes localidades, determinar uma sistemática para classificar os municípios de acordo com sua propensão à criminalidade e, a partir daí, sugerir políticas de segurança adequadas para cada área, além de gerar novas informações que possam ser utilizadas no setor de segurança pública.

Assim, a importância deste artigo se dá pela utilização de uma nova forma de analisar os dados existentes. Por exemplo, o IPEA (Instituto de Pesquisa Econômica Aplicada) publica anualmente o Atlas da Violência, que traz informações sobre a criminalidade no país. Entretanto, a análise é baseada no Estados, e não identifica as especificidades dos municípios. Além disso, são expostas informações separadas por tipo de crime (homicídios, roubos, furtos), e não há uma análise conjunta sobre a propensão à criminalidade. Ademais, o IBGE (Instituto Brasileiro de Geografia e Estatística) dispõe de dados que possuem grande relação com a criminalidade, tais como densidade demográfica e infraestrutura, mas não realiza avaliações sobre como tais fatores influenciam no nível de criminalidade dos municípios. Neste sentido, esta pesquisa utiliza dados do IBGE para analisar a propensão dos municípios à criminalidade e, a partir daí, determinar políticas para a diminuição da violência, considerando as especificidades de cada município e podendo auxiliar órgãos responsáveis pela segurança pública, como uma alternativa para avaliação da propensão ao crime em diferentes regiões e estruturação de ações de controle e combate à violência.

Ademais, apesar da existência de modelos multicritério na área de segurança pública, alguns deles, tais como os propostos por Gurgel et al. (2014) e Araújo e Bezerra (2018) realizam a ordenação das alternativas, o que não está de acordo com os objetivos desta pesquisa, que é de classificar os municípios de acordo com a propensão à criminalidade. Além disso, modelos como o DSRA, empregado por Figueiredo et al. (2015) e Figueiredo e Mota (2016) necessitam do uso de várias regras de dominância, o que os torna complexos para uso do decisor. Assim, esta pesquisa visa propor a utilização de uma sistemática de fácil uso e que resulte em decisões adequadas. 
Desta forma, propõe-se um modelo multicritério de apoio à decisão, baseado no PROMSORT, método da família PROMETHEE (Preference Ranking Organisation Method for Enrichment) para problemas de classificação (SORTing), a fim de categorizar municípios em classes pré-definidas, de acordo com a sua propensão à criminalidade. Este método surge como uma solução eficaz e prática para esse tipo de problema, pois gera uma classificação, através de pesos e critérios determinados, das alternativas propostas, servindo de base para formar um conjunto de ações e auxiliar na tomada de decisão, priorizando a urgência e particularidade do problema de cada localidade. O modelo foi aplicado nas cidades do Estado da Paraíba. Os dados para a aplicação foram embasados em dados governamentais disponibilizados pelo Instituto Brasileiro de Geografia e Estatística, a fim de garantir a veracidade e confiabilidade da pesquisa.

\section{Criminalidade na Paraíba}

Segundo Waiselfisz (2012), a Paraíba sempre apareceu entre os Estados com baixos índices de homicídios no contexto nacional, mas ingressou numa forte escalada de violência, que levou o Estado, em 2010, a figurar entre os seis mais violentos do Brasil. O autor afirma que ocorreram duas fases na evolução da violência no Estado. No primeiro período (de 1980 a 2004), as taxas de homicídios se localizavam abaixo das médias nacionais, enquanto no segundo (2004-2010), o Estado registrou um intenso crescimento em suas taxas, que em poucos anos superou a média nacional. Já em 2010, Waiselfisz (2012) comenta que a Paraíba estava presente no grupo das unidades de elevada violência. $\mathrm{O}$ autor ainda expõe que nessa fase as taxas do Estado mais que duplicaram em seis anos, passando de 18,6 para 38,6 homicídios para cada 100 mil habitantes. A Figura 1 expõe a relação entre as taxas de homicídio no Brasil, Paraíba (UF), Região Metropolitana (C+RM) e Interior do Estado entre os anos de 1980 e 2010.

Figura 1: Taxas de Homicídio por Área. Paraíba. 1980/2010*.



Entretanto, a Paraíba mostrou diminuições gradativas nas taxas de homicídios. Em 2011, foi lançado o programa "Paraíba Unida pela Paz". De acordo com Cerqueira et al. (2018), naquele ano, o Estado ocupava o $3^{\circ}$ lugar de UF mais violenta do país, enquanto em 2016 era o $18^{\circ}$ mais violento. Segundo o IPEA (2019), houve uma diminuição significativa no número de homicídios do Estado por cinco anos consecutivos, o que pode ser observado na Tabela 1. 
Tabela 1: Baixa no número de homicídios no Estado da Paraíba após a implantação do Programa Paraíba Unida pela Paz (2011/2016).

\begin{tabular}{l|c|c|c|c|c|c}
\hline & \multicolumn{7}{|c}{ ANO } \\
\hline & $\mathbf{2 0 1 1}$ & $\mathbf{2 0 1 2}$ & $\mathbf{2 0 1 3}$ & $\mathbf{2 0 1 4}$ & $\mathbf{2 0 1 5}$ & $\mathbf{2 0 1 6}$ \\
\hline $\begin{array}{l}\text { NÚMERO DE } \\
\text { HOMICÍDIOS }\end{array}$ & 614 & 525 & 551 & 551 & 522 & 355 \\
\hline
\end{tabular}

Fonte: Adaptado de IPEA (2019).

Com relação aos roubos, o Fórum Brasileiro de Segurança Pública (2018) demonstra que seus números são alarmantes, com um aumento em quase todas as categorias presentes entre os anos de 2016 e 2017, tendo uma diminuição apenas nas categorias de roubo a estabelecimento comercial e roubo a transeunte, que é a categoria com maior índice nos dois períodos. As Figuras 2 e 3 expõem os dados sobre roubos na Paraíba nos anos citados.

Figura 2: Roubos na Paraíba.

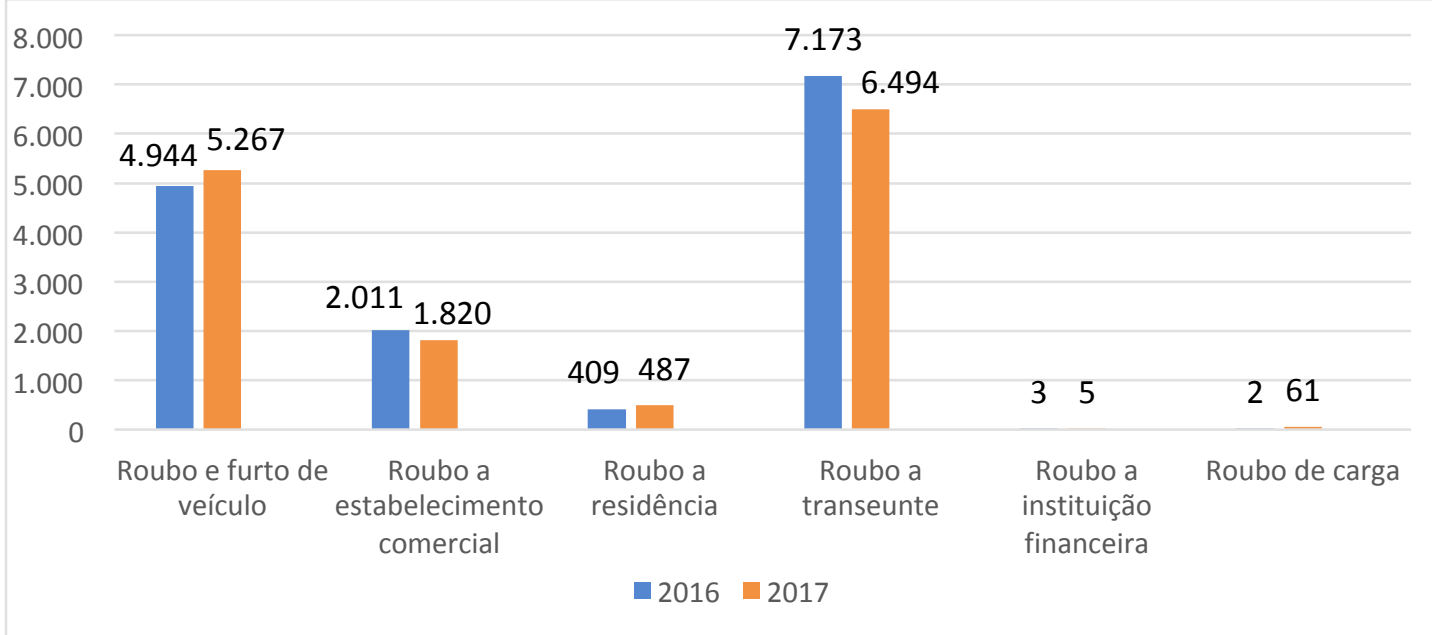

Fonte: Adaptado de Fórum Brasileiro Anuário de Segurança Pública (2018).

Figura 3: Total de roubos na Paraíba.

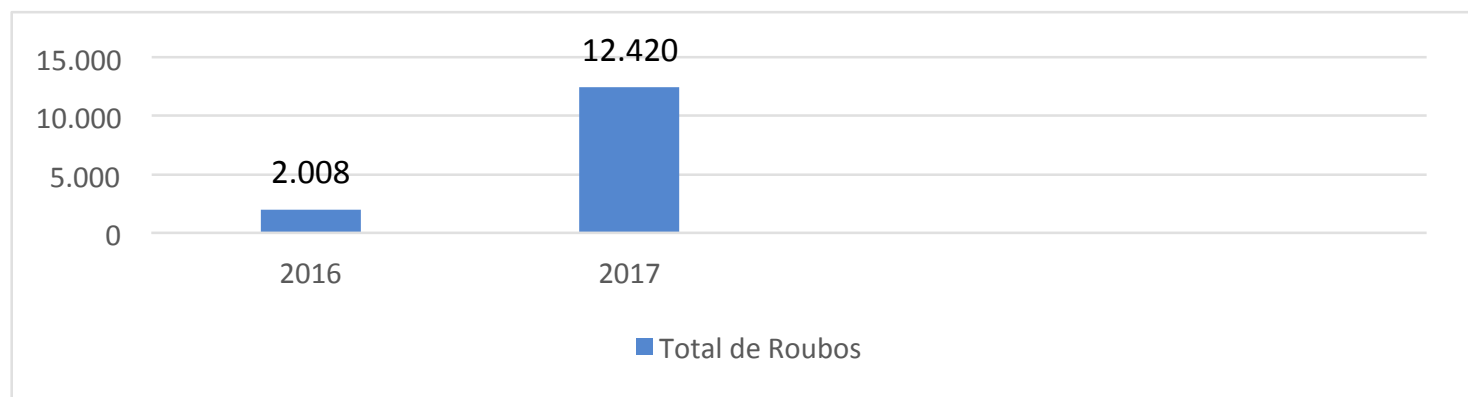

Fonte: Adaptado de Fórum Brasileiro Anuário de Segurança Pública (2018).

Observando os números de roubos gerais, nota-se que houve um aumento de 514,5\% no ano de 2017, sendo um número bem expressivo e preocupante, tendo em vista que o Programa Paraíba Unida pela Paz já foi implementado e resultou, aparentemente, apenas na diminuição dos números de homicídios.

Assim, é evidente que o estudo de medidas para a diminuição dessas taxas é necessário, pois observa-se que o programa não conseguiu abranger todos os âmbitos relacionados a violência no Estado. 


\section{Métodos e Critérios para Análise de Criminalidade}

A violência gera diversos problemas para a população, sejam eles financeiros ou psicológicos. Portanto, é necessária a determinação de ações que visem diminuir os índices de criminalidade. Para obter resultados adequados, tais decisões devem ser tomadas com base em métodos estruturados. Devido à necessidade de considerar vários fatores para análise, os Métodos Multicritério são utilizados por vários autores para auxiliar nas tomadas de decisão quanto a questões de segurança pública, tais como o patrulhamento policial eficaz, alocação de unidades policiais, entre outros.

Oliveira et al. (2015) empregaram o MACBETH (Measuring Attractiveness by a Categorical Based Evaluation Technique) para alocação de postos policiais de observação na cidade de Natal (Rio Grande do Norte), enquanto Araújo e Bezerra (2018) utilizaram o PROMETHEE II para determinar em quais regiões do município de Assú (Rio Grande do Norte) deveriam ser construídos postos de polícia comunitária. Em ambos os casos, os autores ordenaram as regiões da cidade de maneira decrescente, quanto aos níveis de criminalidade, e propuseram a instalação dos postos nas regiões mais violentas.

Gurgel et al. (2014) empregaram o ELECTRE TRI para a classificação das zonas de um município quanto à criminalidade e, em seguida, determinaram quais áreas da cidade necessitavam de maiores investimentos, de acordo com o nível de violência apresentados. Já Gurgel et al. (2011) utilizaram o SMARTS (Simple Multi-Attribute Rating Technique) para a determinação das áreas da cidade com maior índice de violência, a fim de identificar em quais regiões da cidade devem ser focadas as ações de combate à criminalidade.

Figueiredo et al. (2015) propuseram um modelo, baseado no método DSRA (Dominancebased Rough Set Approach), para mapear as localidades mais violentas no município de Recife (Pernambuco). Ademais, Figueiredo e Mota (2016) utilizaram este método para determinar as regiões mais favoráveis à ocorrência de roubos em um município, categorizando-as de acordo com 5 níveis de propensão ao roubo: muito alta, alta, moderada, baixa e muito baixa.

Além da escolha do método adequado para avaliação, outra questão importante é a identificação dos fatores que influenciam a criminalidade, pois o uso de critérios inapropriados resultará em decisões incorretas. Neste contexto, vários autores procuraram elaborar modelos para explicar a violência, cujo enfoque se dá nos níveis estrutural, institucional, interpessoal e individual (Cerqueira e Lobão, 2004). Várias pesquisas buscaram entender a etiologia de dinâmicas criminais específicas, como Belsky (1980), que se preocupou com o abuso infantil; Edleson e Tolman (1992), que estudaram a violência doméstica contra a mulher; e AdamsCurtis e Forbes (2004) cujo estudo foi voltado para a coerção sexual.

Neste sentido, realizou-se uma revisão da literatura para criar uma base de dados sobre os fatores que influenciam a criminalidade, que pode auxiliar na escolha dos critérios para aplicação do modelo proposto. Assim, o Quadro 1 expõe todos os fatores identificados na literatura analisada. Vale salientar que o decisor deverá analisar quais critérios são adequados às suas necessidades, assim como os dados disponíveis para sua utilização.

Identificou-se que a maioria dos critérios está ligada as condições sociais em que a população vive, se esta tem acesso as condições básicas necessárias para viver dignamente, principalmente questões relacionadas à carência financeira e analfabetismo. Entre os fatores apresentados na pesquisa, os mais utilizados são o índice de Gini, renda per capita, densidade demográfica, grau de escolaridade e desemprego.

Além disso, os autores utilizam mais de um critério em seus estudos, o que demonstra a necessidade de utilização de métodos de decisão multicritério em trabalhos que consideram a criminalidade para determinação de políticas públicas. 
Quadro 1: Fatores relacionados à criminalidade.

\begin{tabular}{|c|c|c|}
\hline Critérios & Definição & Autores \\
\hline Índice de Gini & $\begin{array}{l}\text { Instrumento para medir o grau de concentração } \\
\text { de renda em determinado grupo. Ele aponta a } \\
\text { diferença entre os rendimentos dos mais pobres } \\
\text { e dos mais ricos (IPEA, 2019). }\end{array}$ & $\begin{array}{l}\text { Figueiredo e Mota (2016); } \\
\text { Figueiredo (2013); Gurgel e Mota } \\
\text { (2013); Gurgel et al. (2012); } \\
\text { Bezerra Filho et al. (2015) }\end{array}$ \\
\hline Renda per capita & $\begin{array}{l}\text { Indicador socioeconômico que avalia o grau de } \\
\text { desenvolvimento econômico de um } \\
\text { determinado lugar (Figueiredo et al., 2015) }\end{array}$ & $\begin{array}{l}\text { Figueiredo et al. (2015); Gurgel } \\
\text { et al. (2014); Figueiredo et al. } \\
\text { (2017); Bezerra Filho et al. } \\
\text { (2015) }\end{array}$ \\
\hline $\begin{array}{l}\text { Saneamento } \\
\text { básico }\end{array}$ & $\begin{array}{l}\text { Conjunto de medidas que visa prevenir doenças } \\
\text { e promover a saúde, melhorar a qualidade de } \\
\text { vida da população e à produtividade do } \\
\text { indivíduo (Bezerra Filho et al., 2015). }\end{array}$ & Bezerra Filho et al. (2015) \\
\hline Infraestrutura & $\begin{array}{l}\text { Conjunto de elementos estruturais que } \\
\text { impulsiona o desenvolvimento socioeconômico } \\
\text { de um determinado local. }\end{array}$ & $\begin{array}{l}\text { Figueiredo e Mota (2016); } \\
\text { Bezerra Filho et al. (2015) }\end{array}$ \\
\hline Educação & $\begin{array}{l}\text { A formação do sujeito-cidadão, plenamente } \\
\text { capaz de entender sua realidade (L'Apiccirella } \\
(2003) \text {. }\end{array}$ & $\begin{array}{l}\text { L'Apiccirella (2003); Bezerra } \\
\text { Filho et al. (2015) }\end{array}$ \\
\hline $\begin{array}{l}\text { Densidade } \\
\text { demográfica }\end{array}$ & $\begin{array}{l}\text { A densidade demográfica consiste na medida } \\
\text { dada entre o número de habitantes por } \\
\text { quilômetro quadrado: habitante por } \mathrm{km}^{2} \\
\text { (Figueiredo e Mota, 2016) }\end{array}$ & $\begin{array}{l}\text { Gurgel et al. (2012); Entorf e } \\
\text { Spengler (2000); Figueiredo e } \\
\text { Mota (2016); }\end{array}$ \\
\hline $\begin{array}{c}\text { Grau de } \\
\text { escolaridade }\end{array}$ & $\begin{array}{l}\text { Nível de escolaridade que determinado } \\
\text { indivíduo possui. }\end{array}$ & $\begin{array}{l}\text { Figueiredo et al. (2017); } \\
\text { Figueiredo et al. (2015) }\end{array}$ \\
\hline $\begin{array}{c}\text { Taxa de } \\
\text { natalidade }\end{array}$ & $\begin{array}{l}\text { A taxa de natalidade representa o número de } \\
\text { crianças nascidas vivas no período de um ano } \\
\text { (Gurgel et al., 2014). }\end{array}$ & $\begin{array}{l}\text { Gurgel et al. (2014); Gurgel et al. } \\
\text { (2012) }\end{array}$ \\
\hline Desemprego & $\begin{array}{l}\text { Taxa de indivíduos que não possuem um } \\
\text { emprego. }\end{array}$ & $\begin{array}{c}\text { Gurgel et al. (2014); Entorf e } \\
\text { Spengler (2000); Cerqueira e } \\
\text { Lobão (2004) }\end{array}$ \\
\hline IDH & $\begin{array}{l}\text { Unidade de medida utilizada para aferir o grau } \\
\text { de desenvolvimento de uma determinada } \\
\text { sociedade nos quesitos de educação, saúde e } \\
\text { renda (Gurgel et al., 2012). }\end{array}$ & $\begin{array}{l}\text { Gurgel et al. (2012); Bezerra } \\
\text { Filho et al. (2015) }\end{array}$ \\
\hline $\begin{array}{l}\text { Concentração de } \\
\text { renda }\end{array}$ & $\begin{array}{l}\text { Distribuição desigual de renda por unidade } \\
\text { residencial ou indivíduo entre os diferentes } \\
\text { participantes de uma economia (Bezerra Filho } \\
\text { et al., 2015). }\end{array}$ & Gurgel et al. (2012) \\
\hline $\begin{array}{c}\text { Taxa de } \\
\text { punibilidade }\end{array}$ & $\begin{array}{l}\text { Possibilidade Jurídica de aplicação da Sanção } \\
\text { Penal. }\end{array}$ & Bezerra Filho et al. (2015) \\
\hline $\begin{array}{l}\text { Crescimento da } \\
\text { população }\end{array}$ & $\begin{array}{l}\text { O crescimento populacional de um determinado } \\
\text { território ocorre através de dois fatores: a } \\
\text { migração e o crescimento vegetativo (Gurgel et } \\
\text { al., 2012). }\end{array}$ & Gurgel et al. (2012) \\
\hline $\begin{array}{c}\text { Grau de } \\
\text { ocorrências } \\
\text { policiais } \\
\end{array}$ & $\begin{array}{l}\text { Quantidade de vezes em que são registradas } \\
\text { ocorrências policiais. }\end{array}$ & Gurgel et al. (2012) \\
\hline
\end{tabular}

Fonte: Elaborada pelas autoras.

\section{Metodologia}

Esta seção descreve as premissas metodológicas empregadas para o desenvolvimento da pesquisa. 


\subsection{Método PROMSORT}

Silva (2012) relata que a Família de métodos PROMETHEE se divide em: PROMETHEE I, PROMETHEE II, PROMETHEE III, PROMETHEE IV, PROMETHEE V, PROMETHEE VI e PROMSORT. Neste artigo será abordado o método PROMOSORT. Em sua metodologia, são empregados os princípios da metodologia do PROMETHEE I (Brans et al., 1984).

O PROMSORT é um método baseado na família PROMETHEE, que "atribui alternativas a categorias ordenadas predefinidas" (Araz et al., 2007). O autor ainda explica que a atribuição de uma alternativa $a$ resulta da comparação de $a$ com os perfis que definem os limites das categorias. Segundo Almeida (2013), é um método de sobreclassificação valorada, com base em conceitos que podem ser interpretados pelo decisor. $\mathrm{O}$ autor afirma que esse método é baseado na comparação par a par entre as alternativas, explorando uma relação de sobreclassificação que tem algumas características que se distinguem fortemente dos métodos de agregação por meio de critério único de síntese.

Em seu estudo Araz e Ozkarahan (2007) descrevem o método como segue: Seja G um conjunto de critérios $g 1, g 2, \ldots, g j(G=\{1,2, \ldots, j\})$ e seja $B$ um conjunto de perfis limites distinguindo $K+1$ categorias $(B=\{1,2, \ldots, k\}) . b_{h}$ representa o limite superior da categoria $C_{h}$ e o limite inferior da categoria $C_{h}+1, h=1,2, \ldots, k$. Assumindo-se que $C 2>C 1$ significa que a categoria 2 sobreclassifica a categoria 1 , o conjunto de perfis $(B=\{b 1, b 2, \ldots, b k\})$ deve ter a seguinte propriedade:

$$
\left[b_{k} P b_{k-1}\right],\left[b_{k-1} P b_{k-2}\right], \ldots,\left[b_{2} P b_{1}\right]
$$

Onde, $P$ é a preferência. Essa propriedade significa que as categorias devem ser ordenadas e distintas. Assumindo que mais é preferível a menos, as seguintes condições auxiliam a obter as categorias ordenadas e distintas:

$$
\forall_{j}, \forall_{h}=1, \ldots, k ; g_{j}\left(b_{h}+1\right) \geq g_{j}\left(b_{h}\right)+p_{j}
$$

Dessa forma o método PROMSORT é dado em três fases as quais atribuem as alternativas para cada categoria.

- Fase 1 - Construção de uma relação de sobreclassificação utilizando o PROMETHEE I: a primeira etapa para a determinação das alternativas de referência é a comparação de todas as alternativas com os perfis limites, utilizando a relação de sobreclassificação do PROMETHEE.

- Fase 2 - Atribuições das alternativas: A atribuição de alternativas para as categorias resulta diretamente da relação de sobreclassificação (assumindo que $C_{2}>C_{1}$ significa que a categoria 2 sobreclassifica a categoria 1 ).

- Compara-se a alternativa sucessivamente com $b_{i}$, para $i=k, k-1, \ldots, 1$;

- $b_{h}$ será o primeiro perfil no qual $a P b_{h}$

- $b_{t}$ será o primeiro perfil tal que $a R b_{t}$ ou $a I b_{t}$

- Se $h>t$, atribua a à categoria $C_{h+1}$. Ao contrário, não atribua a qualquer alternativa.

$\mathrm{Na}$ próxima etapa, as alternativas que já foram designadas a categorias específicas serão usadas para atribuir as alternativas que ainda não foram direcionadas.

- Fase 3 - Atribuição final: as alternativas $\left(C_{h+1}>C_{h}>\ldots>C_{1}\right)$ são as alternativas de referência para as categorias ordenadas. Suponha que um conjunto referência $X_{h}$ consiste em $\mathrm{m}$ das alternativas para a categoria $\mathrm{h}$, ou seja, $\left\{X=x_{1}, x_{2}, \ldots, x_{m}\right\}$. Para uma alternativa a que ainda não foi atribuída a nenhuma categoria: 
- Determine a distância

$d_{k}=\frac{1}{n_{t}} d_{k}^{+}-\frac{1}{n_{t+1}} d_{k}^{-}$

Onde,

$d_{k}^{+}$mensura a característica de sobreclassificação de a sobre todas as alternativas atribuídas à classe $C_{t}$

$d_{k}^{-}$mensura a característica a sendo sobreclassificação de a sobre todas as alternativas atribuídas à classe $C_{t+1}$

$n_{t}$ é o número de alternativas de referência da categoria $C_{t}$.

Atribua um ponto de corte sobre b. Se a distância é maior que o ponto de corte, atribua a alternativa a à categoria $C_{t+1}$, se não atribua a $C_{t}$. Aqui, b pode ser especificado pelo decisor e reflete o ponto de vista do decisor: pessimista ou otimista.

Segundo Araz e Okzarahan (2007), as principais vantagens deste método são a flexibilidade e a facilidade de uso, enquanto a maior desvantagem é a necessidade de uma quantidade considerável de informações.

\subsection{Critérios para Análise de Propensão à Criminalidade}

Para uma classificação adequada dos municípios, é necessário que se avaliem os critérios que possuem relação com a criminalidade, pois, se utilizarmos inputs inadequados no modelo de decisão, os resultados serão inapropriados. Assim, para a escolha dos fatores a considerar no modelo, inicialmente analisou-se a revisão da literatura, observando-se quais critérios foram identificados em pesquisas anteriores, conforme o Quadro 1.

Em seguida, buscou-se por fontes de dados confiáveis para análise, considerando a necessidade de informações sobre todos os municípios do Estado. De forma que um determinado critério só pode ser utilizado se houver dados disponíveis para todas as alternativas (municípios). Neste sentido, considerou-se os dados presentes no site do IBGE como adequados para o uso, pois são estruturados a partir de uma pesquisa extensiva e possuem informações sobre todas as cidades do país.

Assim, os critérios analisados, escolhidos devido à frequência com a qual aparecem na literatura e pela disponibilidade de dados, foram: densidade demográfica, educação, infraestrutura e renda per capita. A definição destes, conforme Araújo e Bezerra (2018), a decodificação e a necessidade de maximização ou minimização, são expostas no Quadro 2.

Para a análise da densidade demográfica utilizou-se os dados apresentados pelo IBGE, referentes ao Censo de 2010, equivalentes ao número de habitantes por $\mathrm{km}^{2}$. Para o cálculo do critério educação, utilizou-se os dados referente a alfabetização dos habitantes com 5 ou mais anos de idade, e o número de habitantes do município, conforme a Equação 3.

$$
\text { Pessoas alfabetizadas }=\frac{N^{\circ} \text { de pessoas alfabetizadas }}{N^{\circ} \text { de habitantes }}
$$


Quadro 2: Critérios de Avaliação.

\begin{tabular}{|c|c|lc|c|}
\hline Código & Critérios & \multicolumn{1}{|c|}{ Definição } & Max/Min \\
\hline C1 & $\begin{array}{c}\text { Densidade } \\
\text { demográfica }\end{array}$ & $\begin{array}{l}\text { Corresponde ao número de pessoas, por quilômetro quadrado, } \\
\text { que habita em uma área, região ou país (Panitz, 2003). }\end{array}$ & Minimizar \\
\hline C2 & Educação & $\begin{array}{l}\text { De acordo com Fulgencio (2007) uma pessoa alfabetizada é } \\
\text { aquela capaz de ler e escrever, no idioma que conhece, um } \\
\text { bilhete. }\end{array}$ & Maximizar \\
\hline C3 & Infraestrutura & $\begin{array}{l}\text { Está relacionada a infraestrutura dos domicílios, mais } \\
\text { precisamente a existências de banheiro e abastecimento de água. } \\
\text { Conforme a Lei no 11.445/2007 o saneamento básico é } \\
\text { caracterizado como sendo um conjunto de serviços de } \\
\text { abastecimento de água potável, esgotamento sanitário, limpeza } \\
\text { urbana e gestão dos resíduos e drenagem e condução das águas } \\
\text { pluviais. }\end{array}$ & Maximar \\
\hline C4 & $\begin{array}{l}\text { Renda Per } \\
\text { capita }\end{array}$ & $\begin{array}{l}\text { Conforme Fulgencio (2007) a renda per capita é o valor que } \\
\text { cada habitante de uma região receberia caso houvesse uma } \\
\text { distribuição igual do valor do Produto Nacional Bruto (PNB) } \\
\text { entre todos os indivíduos, não considerando a concentração de } \\
\text { riquezas. }\end{array}$ & Maximizar \\
\hline
\end{tabular}

Fonte: Araújo e Bezerra (2018).

Para a infraestrutura, avaliou-se o número de residências presentes na cidade, a quantidade de domicílios que possuem banheiro e a quantidade de domicílios que possuem água encanada (Equação 4). A Equação 5 determina a porcentagem de municípios com infraestrutura adequada. Quanto maior o resultado, melhor a avaliação do quesito.

( $N^{\circ}$ de domicílios com banheiros)

$+$

Média de domicílios $=\frac{\left(N^{\circ} \text { de domicílios com água encanada }\right)}{2}$

$\%=\frac{\text { Média }}{N^{\circ} \text { total de domicílios do município }}$

Para calcular a renda per capita utilizou-se as informações alusivas ao número de habitantes de cada município e o número de pessoas que recebem a quantidade de salários. Empregou-se a Equação 6 para o cálculo:

Renda per capita $=\frac{\sum \text { salários }}{N^{\circ} \text { de habitantes do município }}$

Os critérios determinados possuem alta relevância e influência sobre o grau violência de determinada localidade, como exposto na revisão da literatura. O diferencial do método está na agregação destes critérios durante a avaliação. Assim, pode-se avaliar qual a importância relativa de cada critério quanto à sua influência na propensão à criminalidade durante a análise conjunta dos dados. Outra questão importante da agregação é que, mesmo sendo de senso comum que algumas destas questões influenciem a violência, estas normalmente são avaliadas separadamente, enquanto o modelo proposto faz uma avaliação conjunta, expondo um panorama geral. Além disso, a classificação quanto aos níveis de criminalidade facilita o planejamento de políticas, quando comparado a um ranking de alternativas, já que se considera as especificidades dos municípios de determinada classe em conjunto. 


\section{Modelo para Classificação das Cidades de acordo com a Propensão à Criminalidade}

De acordo com Cerqueira et al. (2018), o crescente índice de violência revela, além da naturalização do fenômeno, a premência de ações compromissadas e efetivas por parte das autoridades nos três níveis de governo: federal, estadual e municipal. O desafio é grande, afinal trata-se de uma complexa agenda da segurança pública, que deve envolver ações intersetoriais e integradas que incluam, além dos executivos, o Parlamento, a Justiça, o Ministério Público, a Defensoria e a academia, os empresários e toda a sociedade civil organizada (Cerqueira et al., 2018). Dessa forma, nota-se que ferramentas que auxiliem o Estado na determinação de políticas públicas adequadas são necessárias, pois são mais assertivas e darão uma maior credibilidade ao trabalho desenvolvido.

Entender quais os principais critérios que levam à criminalidade e criar estratégias e formas de lidar com eles é um passo para o combate à violência e uma forma de promover uma maior sensação de segurança à população. Neste sentido, o modelo aqui proposto (Figura 4) visa a classificação das cidades quanto a sua propensão a criminalidade, e apresenta algumas sugestões de políticas de segurança que, se adotadas pelas autoridades, acarretarão a diminuição dos índices de violência, melhorando a qualidade de vida dos cidadãos.

Figura 4: Sistemática do modelo proposto.

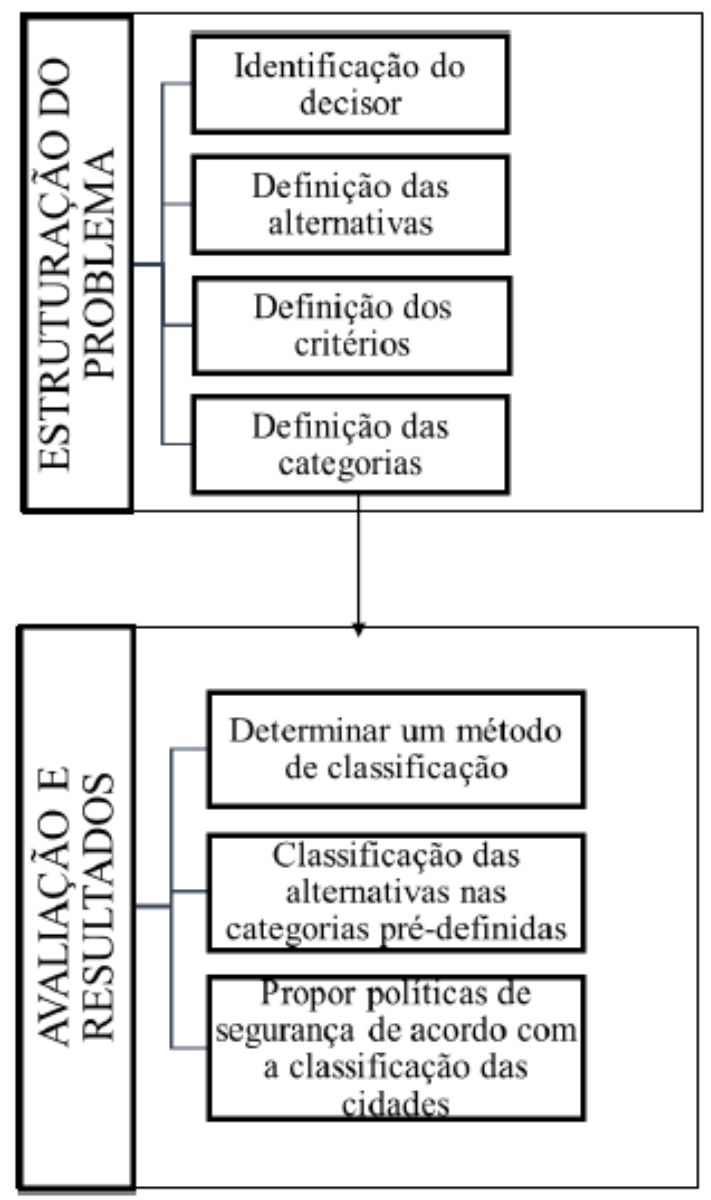

Fonte: Elaborada pelas autoras.

Tendo em vista que os recursos são escassos, o modelo auxiliará o decisor a ter uma real noção da situação de violência para traçar planos, priorizar os pontos críticos do Estado, e organizar os recursos, disponibilizando-os para cada área a ser trabalhada. 


\subsection{Descrição do Modelo}

$\mathrm{Na}$ fase de estruturação do problema, inicialmente, deve-se identificar o decisor, podendo ser alguém ligado a gestão governamental e de segurança pública, tais como policial, secretário de segurança ou governador, para que, de acordo com a sua experiência, ele possa garantir que o resultado do modelo seja satisfatório. Doumpos \& Zopounidis (2004), relatam que o maior objetivo do AMD é fornecer um conjunto de metodologias de agregação de critérios, que possibilitem o desenvolvimento de modelos de suporte à decisão, considerando o sistema de preferência e o julgamento do decisor, a partir da implementação de processos complexos que não lidam com soluções ótimas, mas com soluções satisfatórias de acordo com as preferências do indivíduo. Em seguida, são identificadas e definidas as alternativas, podendo ser municípios, Estados ou países, que serão classificados de acordo com a sua propensão a criminalidade.

Posteriormente, são definidos os critérios. Esta identificação pode ser realizada a partir da apresentação dos critérios identificados na revisão da literatura ao decisor que, a partir destes fatores e de sua experiência e dados disponíveis, determinará, de acordo com suas preferências, os critérios que melhor representam o problema abordado no estudo. De acordo com Araújo e Alencar (2015), em casos nos quais existe apenas um decisor, o mesmo deve considerar suas preferências e as dos demais atores, assim como os objetivos da organização de forma geral, enquanto em situações com maior divergência entre as opiniões, é interessante utilizar procedimentos de decisão em grupo. No caso de um único decisor, pode-se utilizar o auxílio do analista (Araújo e Bezerra, 2018). Estabelecidos os critérios, a coleta de dados necessários para realizar essa avaliação pode ser realizada, por exemplo, através de sites governamentais, a fim de assegurar a veracidade dos resultados da pesquisa.

Por fim, são definidas as categorias. Barité (1998) expõe que as categorias precisam ser revisitadas, tanto em sua definição como em sua justificativa e aplicação. Conforme a grande quantidade de alternativas existentes no modelo, observou-se que quanto maior a necessidade de especificação das classes, maior o número de categorias. Uma alternativa de classificação, proposta nesta pesquisa é:

- Muito alta: categoria destinada as alternativas que dispõe dos piores resultados, apresentando os maiores índices de criminalidade, ou seja, a segurança é altamente falha e há necessidade de políticas urgentes para a redução da criminalidade.

- Alta: nesta categoria estão alocadas as alternativas que apresentaram resultados negativos possuindo alto grau de criminalidade, porém menor do que a categoria anterior.

- Média: as alternativas que se classificam nesta categoria possuem índices de criminalidade que não são muito altos, mas ainda são preocupantes.

- Baixa: alternativas que detêm índices de criminalidade baixos em relação as outras, ou seja, o estado da segurança pública não é alarmante.

- Muito baixa: aqui estão as alternativas que apresentaram os melhores índices, ou seja, não possui grandes problemas com a segurança nem índices graves de criminalidade.

Através dessas classes, o decisor poderá determinar os níveis de propensão à criminalidade dos municípios do Estado e, a partir daí, determinar quais políticas de segurança serão tomadas e priorizar os locais com maior urgência de implantação.

$\mathrm{Na}$ segunda etapa, avaliação dos resultados, analisa-se as alternativas e determina-se o método de classificação. O método precisa considerar vários critérios para realizar a classificação pois existem inúmeros fatores que influenciam na criminalidade, assim os resultados corresponderão a realidade dos municípios diante desse problema. Como os critérios definidos na etapa anterior podem ser objetivos ou subjetivos, o método escolhido deve lidar adequadamente com variáveis quantitativas e qualitativas, como também com a incerteza inerente ao processo decisório (Araújo et al., 2015).

Desta forma, propõem-se a utilização do PROMSORT, que é uma extensão do PROMETHEE, para problemas de classificação e utiliza os princípios metodológicos do 
PROMETHEE I, atribuindo alternativas a categorias ordenadas previamente definidas. O método é adequado ao problema devido às seguintes características:

- Realiza uma classificação, na qual categoriza as alternativas de acordo com os critérios determinados.

- Este é um método não compensatório, ou seja, não existe a compensação de uma alternativa que apresenta menor desempenho por outra que apresenta maior, dessa maneira, os resultados apresentam uma visão real da situação dos municípios.

- É flexível, devido à possibilidade de escolha entre as diversas funções de critérios generalizados e de fácil uso;

- Utiliza os conceitos de perfis limites e alternativas e referências, de acordo com as preferências do decisor;

- Oferece ao decisor flexibilidade para definir o ponto de vista otimista e pessimista;

- Usa também método de concepção e ordenação aplicável em várias situações e diferenças de cada alternativa confirmadas através da avaliação de critérios por função de preferência (Silva et al., 2010).

Assim, as alternativas serão alocadas de acordo com seus resultados em suas respectivas categorias pré-definidas. Depois dessa etapa, os resultados serão avaliados e assim propostas políticas de segurança serão apontadas a fim de que sejam adotadas para a minimização da criminalidade presente nas cidades do Estado da Paraíba.

A partir da classificação das cidades feita pelo software, apresenta-se a classificação dos municípios segundo o nível de propensão a criminalidade do Estado da Paraíba. Posteriormente, serão decididas quais as políticas de segurança a serem propostas e onde serão implantadas primeiras, de acordo com as circunstâncias dos cenários observados em cada um deles.

\subsection{Aplicação}

O modelo tratado na presente pesquisa foi aplicado no Estado da Paraíba, localizado no Nordeste do Brasil. O Estado, segundo o último censo do IBGE, possui 223 municípios, com uma população de 3.766 .528 milhões de habitantes e densidade demográfica de 66,70 habitantes $/ \mathrm{km} 2$. Segundo Cerqueira et al. (2018), a Paraíba está na $18^{\circ}$ posição no ranking dos Estados mais violentos do País, visto que teve uma evolução, pois ocupava o $3^{\circ}$ lugar. Entretanto, ainda existem vários problemas no quesito segurança, tais como roubos e furtos, crimes contra o patrimônio público, entre outros.

Inicialmente, foram determinados os critérios utilizados como indicativo de propensão à criminalidade, expostos no Quadro 2. Definiu-se que os pesos fossem iguais para todos os critérios, pois não foi realizada uma análise específica sobre as importâncias relativas dos diferentes fatores quanto à propensão à criminalidade. Já para definição da função, foi escolhida a usual, visto que qualquer aumento ou diminuição do desempenho são considerados para a sobreclassificação.

Em seguida foram definidos os perfis limites das categorias, conforme a Tabela 2. Para isto, foram avaliados os valores possíveis de desempenho em cada critério, de acordo com os dados disponíveis no site do IBGE. Analisou-se quais os valores máximos de desempenho para cada classe, que foram considerados os limites superiores da categoria avaliada. Por exemplo, na classe 'muito alta', o limite superior para Infraestrutura é 0,50 , enquanto para Renda de 0,30 .

Tabela 2: Matriz de avaliação dos perfis limites em relação aos critérios.

\begin{tabular}{c|c|c|c|c}
\hline Alternativas & \multicolumn{4}{|c}{ Critérios } \\
\hline & Infraestrutura & Renda & Educação & Densidade \\
\hline L1 & 0,50 & 0,30 & 0,50 & 105 \\
\hline L2 & 0,65 & 0,50 & 0,60 & 55 \\
\hline L3 & 0,80 & 0,70 & 0,70 & 35 \\
\hline L4 & 0,95 & 0,90 & 0,80 & 20 \\
\hline L5 & 1,00 & 1,20 & 0,90 & 5 \\
\hline
\end{tabular}

Fonte: Elaborada pelas autoras. 
Após a coleta de dados, utilizou-se o software Microsoft Excel para determinar o desempenho de cada um dos municípios nos diferentes critérios, com base nos dados do IBGE e nas equações expostas na seção 4.2. Em seguida, empregou-se o Software Promethee-Gaia ${ }^{\circledR}$ para classificar as alternativas nas categorias expostas anteriormente: muito alta, alta, média, baixa e muito baixa. Neste caso, considerou-se a visão otimista para a determinação das classes. Ou seja, os municípios são alocados nas melhores classes possíveis. Desta forma, o software gerou a classificação dos municípios de acordo com a propensão à criminalidade, como exposto no Quadro 3.

Quadro 3: Classificação dos municípios quanto à propensão à criminalidade.

\begin{tabular}{|c|c|}
\hline Categorias & Cidades \\
\hline Muito Alta & $\begin{array}{l}\text { Alagoa Nova, Alagoinha, Araçagi, Arara, Araruna, Areial, Aroeiras, } \\
\text { Assunção, Barra de Santana, Belém, Bernardino Batista, Borborema, Caaporã, } \\
\text { Cacimbas, Casserengue, Conde, Cuité de Mamanguape, Cuitegi, Dus } \\
\text { Estradas, Esperança, Gado Bravo, Itabaiana, Itapororoca, Juarez Távora, } \\
\text { Juripiranga, Lagoa Seca, Lucena, Mamanguape, Mari, Mogeiro, Montadas, } \\
\text { Natuba, Nova Floresta. }\end{array}$ \\
\hline Alta & $\begin{array}{l}\text { Água Branca, Aguiar, Alagoa Grande, Alcantil, Algodão de Jandaíra, } \\
\text { Alhandra, Areia, Areia de Baraúnas, Baía da Traição, Bananeiras, Barra de } \\
\text { Santa Rosa, Bayeux, Belém do Brejo do Cruz, Bom Jesus, Bonito de Santa Fé, } \\
\text { Brejo dos Santos, Cachoeira dos Índios, Cacimba de Dentro, Caiçara, } \\
\text { Cajazeiras, Cajazeirinhas, Caldas Brandão, Capim, Carrapateira, Cruz do } \\
\text { Espírito Santo, Damião, Fagundes, Guarabira, Gurinhém, Ibiara, Imaculada, } \\
\text { Ingá, Itatuba, Jacaraú, Juazeirinho, Lagoa, Lagoa de Dentro, Lastro, } \\
\text { Livramento, Logradouro, Manaíra, Marcação, Marizópolis, Massaranduba, } \\
\text { Mato Grosso, Maturéia, Monte Horebe, Mulungu, Nazerezinho, Nova Olinda, } \\
\text { Patos, Paulista, Pilões, Riachão do Bacamarte, Riachão do Poço, Salgado de } \\
\text { São Félix, São José dos Ramos, São Miguel de Taipu, Serraria, Sobrado, Vista } \\
\text { Serrana. }\end{array}$ \\
\hline Média & $\begin{array}{l}\text { Amparo, Aparecida, Barra de São Miguel, Boa Ventura, Boa Vista, Bom } \\
\text { Sucesso, Boqueirão, Brejo do Cruz, Cabaceiras, Cabedelo, Cacimba de Areia, } \\
\text { Camalaú, Campina Grande, Caraúbas, Catingueira, Catolé do Rocha, Caturité, } \\
\text { Conceição, Condado, Congo, Coremas, Coxixola, Cubati, Cuité, Curral Velho, } \\
\text { Desterro, Diamante, Emas, Frei Martinho, Gurjão, Igaracy, Itaporanga, Jericó, } \\
\text { João Pessoa, Junco do Seridó, Juru, Mãe d'àgua, Malta, Mataraca, Monteiro, } \\
\text { Nova Palmeira, Olho d'água, Olivedos, Ouro Velho, Parari, Passagem, Pedra } \\
\text { Branca, Pedra Lavrada, Pedras de Fogo, Pedro Régis, Pilar, Pilõezinhos, } \\
\text { Piripirituba, Pitimbu, Pocinhos, Poço Dantas, Poço José de Moura, Pombal, } \\
\text { Princesa Isabel, Puxinanã, Queimadas, Quixabá, Remígio, Riachão, Riacho } \\
\text { dos Cavalos, Rio Tinto, Salgadinho, Santa Cecília, Santa Inês, Santa Rita, } \\
\text { Santa Terezinha, Santana de Mangueira, Santana dos Garrotes, Santarém, } \\
\text { Santo André, São Bentinho, São Bento, São Domingos, São Francisco, São } \\
\text { João do Rio de Peixe, São João do Tigre, São José da Lagoa Tapada, São José } \\
\text { de Caiana, São José de Espinharas, São José de Princesa, São José do Bonfim, } \\
\text { São José do Brejo do Cruz, São Sebastião de Lagoa de Roça, Sapé, Seridó, } \\
\text { Serra da Raiz, Serra Grande, Serra Redonda, Sertãozinho, Solânea, Sossêgo, } \\
\text { Sousa, Tacima, Taperoá, Tavares, Teixeira, Tenório, Triunfo, Uiraúna, } \\
\text { Umbuzeiro, Vieirópolis, Zabelê. }\end{array}$ \\
\hline Baixa & Baraúna, Curral de Cima, Dona Inês, Matinhas \\
\hline Muito baixa & $\begin{array}{l}\text { Piancó, Picuí, Prata, Riacho de Santo Antônio, Santa Cruz, Santa Helena, } \\
\text { Santa Luzia, São Domingos do Cariri, São João do Cariri, São José de } \\
\text { Piranhas, São José do Sabugi, São José dos Cordeiros, São Mamede, São } \\
\text { Sebastião do Umbuzeiro, Serra Branca, Soledade, Sumé, Várzea. }\end{array}$ \\
\hline
\end{tabular}

Fonte: Elaborada pelas autoras. 
Observa-se que, devido as regras de atribuição das alternativas propostas no modelo (atribuição e atribuição final), nenhuma das alternativas é atribuída a duas classes, pois, qualquer ambiguidade ocorrida na fase 1 é excluída nas demais etapas. A Figura 5 expõe o mapa com a classificação das cidades quanto à propensão à criminalidade.

Figura 5: Classificação das cidades quanto à propensão à criminalidade.

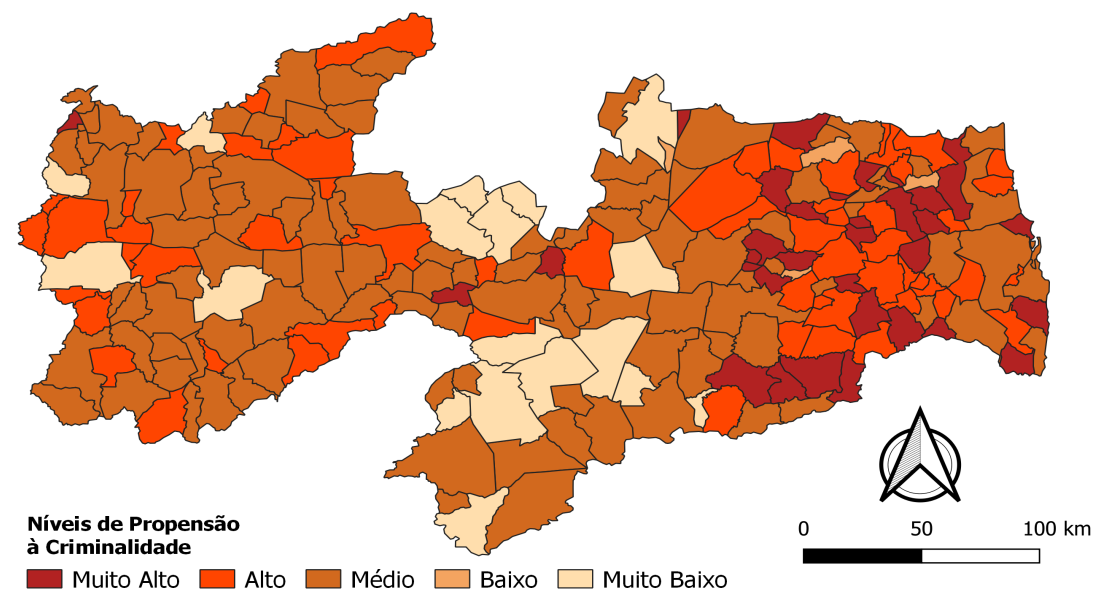

Fonte: Elaborada pelas autoras.

Através do mapa, podemos observar que os municípios classificados na categoria "Muito alto" e "Alto" estão predominantemente localizados entre a região da Mata e Agreste do Estado, os quais possuem uma densidade demográfica alta, a porcentagem de infraestrutura baixa, assim como baixa quantidade de pessoas alfabetizadas e uma renda per capita predominante de meio a um salário mínimo. Já a região da Borborema possui, em sua maioria, as cidades classificadas nas categorias "Médio" e "Muito baixo", o que contraria as suposições de que as cidades do interior, região do Sertão, seriam as que apresentariam os menores índices de violência por conter uma população menor. Nota-se que tais municípios estão entre as categorias "Alto" e "Médio", mostrando como a violência tem se alastrado e atingido o Estado como um todo.

Com essa análise, observa-se que a maior propensão à criminalidade está presente na região Agreste e da Mata Paraibana, onde as políticas de ações devem ser implantadas primeiro, com o objetivo de controlar a situação, e, em seguida, serem implementadas em outras regiões, com caráter menos urgente. Nota-se também que o quadro geral do Estado está relacionado a um índice médio de criminalidade, tendo em vista que as cidades classificadas nesta categoria estão fortemente presentes em todas as regiões. É possível analisar ainda que as cidades classificadas na categoria muito baixa possuem uma boa taxa de pessoas alfabetizadas, uma densidade demográfica relativa, não possuindo mais que 32 habitantes por metro quadrado e uma boa infraestrutura, com um percentual que mostra que quase todas as residências das cidades possuem banheiro e água encanada.

Um estudo feito pelo IPEA (2019) confirma que as duas mesorregiões mais violentas da Paraíba são a Mata Paraibana e o Agreste, como observado no mapa acima, e informa também que os municípios mais violentos do Estado, em 2017, eram Mato Grosso, São João do Tigre, Caaporã e Caldas Brandão, cidades que estão classificadas nas categorias "Muito Alta" e "Alta". A pesquisa também aborda a questão da briga entre facções existentes no Estado como um dos fatores no aumento de violência e assassinatos, mesmo com a atuação qualificada importante do Programa Paraíba Unidos pela Paz. É importante frisar que a pesquisa do IPEA analisa o crime após a ocorrência, enquanto a presente artigo avalia os fatores de propiciam a 
ocorrência do crime. Além disso, a análise do IPEA resulta em um ranking dos municípios, e não a categorização. Assim, não foram identificadas pesquisas que realizem a classificação dos municípios quanto à propensão à criminalidade.

Para validação do modelo foi considerado o método 'Face Validity' que, segundo Leedy e Ormrod (2001), é um julgamento subjetivo de natureza não estatística que observa a opinião dos decisores com relação à validade de um estudo particular. Neste sentido, os resultados do modelo foram expostos para moradores de algumas cidades, tais como Sumé, Alagoa Nova, Jericó, Conde, entre outras, que concordaram com a classificação das cidades.

\subsubsection{Propostas de Políticas de Segurança Pública}

Após a observação dos resultados avaliou-se que o Estado possui um grande número de municípios com alto grau de propensão à criminalidade (94 municípios nas classes 'muito alta' e 'alta'), o que traz a necessidade da utilização de ferramentas para a geração de novos dados e informações sobre a situação da segurança, assim como a proposição e execução de medidas adequadas, com o intuito de amenizar a situação da criminalidade nos municípios. Portanto, as propostas foram pensadas priorizando a urgência de medidas, de acordo com a sua classificação, sendo que os municípios com classificação 'Muito Alta' necessitam de medidas mais urgentes e incisivas, enquanto aqueles na classe 'Muito Baixa', podem considerar ações que maior prazo para visualização de resultados. Neste sentido, tem-se, em aspectos gerais, as seguintes indicações para as categorias:

- Muito Alta: pode-se perceber, através dessa classificação, que há uma grande quantidade de municípios nesta categoria (33 municípios). É importante que as políticas adotadas sejam implantadas rapidamente, pois esses municípios encontram-se em uma situação crítica com relação a criminalidade.

- Alta: nesta categoria encontram-se as cidades que também possuem um nível elevado de criminalidade, tendo prioridade na implantação das medidas, mas com menos urgência que a categoria anterior.

- Média: é a categoria que possui a maior quantidade de municípios classificados pelo software. É preciso analisar e discutir quais as melhores medidas para serem adotadas, com o objetivo de que os municípios saiam desta categoria para as categorias "baixa" e "muito baixa".

- Baixa: as cidades aqui classificadas possuem um baixo índice de propensão à criminalidade, portanto o decisor poderia investigar quais os fatores que influenciam a violência e realizar um planejamento para a adoção de medidas relativas a questões específicas.

- Muito Baixa: esta é a melhor categoria. Aqui foram alocadas as cidades que possuem os menores índices de criminalidade do Estado, ou seja, possuem taxas aceitáveis de densidade demográfica, alfabetização, infraestrutura e renda per capita, de forma que as autoridades devem trabalhar para que esses índices se mantenham.

Neste sentido, em municípios com índice de criminalidade muito alto, deve-se utilizar políticas de segurança pública de mecanismos emergenciais. Inicialmente, deve-se aumentar o número de policiais, considerando a necessidade de repressão aos crimes e estabelecimento da ordem. É importante frisar que o policiamento nos municípios é de responsabilidade das esferas Estadual e Federal. Assim, em caso de contratação de policiais civis e militares, estas cidades devem ser priorizadas.

Ademais, é importante criar unidades de polícia pacificadora nestes municípios. Devido à restrição de recursos para a construção de prédios e contratação de efetivo policial, deve-se priorizar os municípios com maior grau de criminalidade. Neste caso, pode-se utilizar modelos como o de Araújo e Bezerra (2018) para ordenação das cidades e priorização de construção das unidades para aquelas com maiores níveis de violência. Se os recursos forem suficientes para a construção em uma maior quantidade de municípios, após a finalização dos municípios com propensão à criminalidade muito alta, deve-se passar para as de alta propensão, e assim 
sucessivamente. Além disso, as políticas sugeridas para as demais classes devem ser realizadas para esta categoria.

Em municípios com índice de propensão à criminalidade alto, deve haver investimentos em tecnologia para maior cobertura e vistoria de territórios através de drones, assim como aplicativos para informação de ocorrências criminais e acionamento instantâneo da equipe de patrulhamento mais próxima ao local. Dessa forma a polícia poderá trabalhar em conjunto com a comunidade, diminuindo a hostilidade existente naquele ambiente, aumentando o sentimento de segurança e respeito mútuo entre as partes. Além disso, as políticas propostas para categorias de média e baixa propensão devem ser utilizadas nestes municípios.

Em municípios com Média propensão à criminalidade, deve-se realizar blitz sem aviso prévio em diferentes localidades. As blitz devem ser realizadas em locais com maior propensão à criminalidade do município. Para determinar tais locais, pode-se utilizar o método proposto por Araújo e Bezerra (2018). Outra questão importante é a criação de Conselhos Comunitários de Segurança, que objetivam aproximar a população e as autoridades policiais. Nestes casos, a população tem encontros com os chefes de polícia, com sugestões, solicitações, elogios, entre outros. Esta é uma ferramenta de participação popular na segurança pública, de grande importância para aumento do senso de segurança. As políticas propostas para as classes baixa e muito baixa também devem ser consideradas nesta classe.

Com relação aos municípios que englobam as categorias de propensão Baixa e Muito Baixa devem ser realizadas ações preventivas primárias para evitar o aumento das taxas de criminalidade, assim como diminuir tais taxas. Assim, devem ser realizadas políticas de segurança pública distributivas na área da educação. Neste sentido, propõe-se que os programas para jovens e adolescentes já existentes sejam melhorados, com a inserção de cursos de qualificação e a criação de parcerias entre o governo e empresas, para que os jovens possam estagiar nesses locais e assim ingressar no mercado de trabalho, o que dificultaria a entrada para o crime, já que com uma melhor formação e maior grau de escolaridade, as chances de permanência e ascensão no mercado de trabalho aumentam. Além disso, o atendimento psicológico em todas as escolas é necessário para o tratamento das particularidades e realidades de cada aluno, a fim de entender o desinteresse, controlar as grandes evasões escolares e monitorar o trabalho infantil, que é a maior causa deste problema.

Ainda com relação as políticas distributivas, no âmbito da renda per capita, pode-se criar cursos sobre educação financeira para empreender, obtendo uma renda extra ou até mesmo fazendo daquela atividade a sua principal fonte de renda. O controle da densidade demográfica pode ser feito a partir de ações que conscientizam a mulher acerca dos seus direitos e sobre o seu papel fundamental no mercado de trabalho e dentro da família. Outra questão fundamental é a criação de políticas de segurança no combate as drogas, a partir da prevenção do uso, tratamento e reinserção social do usuário.

$\mathrm{Na}$ infraestrutura, devem ser realizadas políticas de segurança pública de caráter redistributivo, ou seja, focar o deslocamento de recursos em determinadas áreas, como, por exemplo, realizar melhorias urbanas em bairros com maior nível de pobreza. Além disso, focar programas de habitação para moradores de rua e pessoas que vivem em condições sub-humanas para que possam exercer trabalhos dentro das próprias comunidades e, posteriormente, fazer algum curso de qualificação.

As ações aqui tratadas são apenas algumas indicações. Observa-se que já existem vários programas governamentais, tais como o PRONASCI que, se implementados de forma adequada, podem trazer reduções significativas na propensão à criminalidade. De forma geral, em categorias 'muito alta' e 'alta', deve-se priorizar ações mais imediatas, tais como aumento do número de policiais e alocação de unidades de polícia. No caso de categorias 'média', 'baixa' e 'muito baixa' priorizam-se ações relacionadas à educação, renda per capita e densidade demográfica.

Vale salientar a importância de, além de mapear os dados sobre propensão à criminalidade, se implemente e monitore a efetividade das ações de políticas públicas nas esferas municipais, estaduais e federal. 


\section{Considerações Finais}

O âmbito da segurança é uma área desafiadora e complexa, pois existem vários fatores que contribuem para a propensão a criminalidade e muitos cenários a serem trabalhados, o que dificulta a resolução desse problema. Esse assunto assombra cada vez mais a população, que busca por formas alternativas de proteção. O Governo também procura, a muito tempo, solucionar ou, ao menos, amenizar essa situação, sem conseguir obter total êxito com essas ações. Assim, é necessária a realização de pesquisas neste âmbito.

Neste sentido, inicialmente foi realizado um levantamento bibliográfico a respeito da segurança pública e identificou-se a necessidade de um modelo que auxilie na tomada de decisão frente aos muitos critérios existentes para a problemática. A partir deste modelo, os responsáveis pela segurança (estadual e municipal) poderão considerar novas maneiras para investigar e classificar a propensão dos municípios à criminalidade, observando como eles se destacam em cada região e, a partir daí, através de questionamentos e análises, eleger as soluções mais adequadas para diminuir os índices de violência. Deve-se entender que este é um problema que não deve ser tratado com soluções universais, pois diferentes localidades possuem níveis de segurança diversos, e esta questão deve ser considerada no momento da tomada de decisão. A partir do planejamento, uma série de passos devem ser estabelecidos, executados, dirigidos e controlados, a fim de propor soluções adequadas para os problemas existentes.

Assim, foi proposto um modelo multicritério de apoio à decisão para a classificação dos municípios de acordo com a sua propensão ao crime, a fim de determinar e priorizar políticas de segurança segundo os níveis de criminalidade. No modelo, foi utilizado o método PROMSORT, caracterizado por ser não compensatório, o que gera resultados equilibrados do desempenho das alternativas, tendo em vista os critérios analisados. Além disso, o método é flexível quanto às necessidades do decisor, de fácil entendimento e pode considerar tanto critério qualitativos quanto quantitativos, aumentando a liberdade do decisor quanto aos fatores a considerar.

Os resultados demonstram que a Paraíba possui, no geral, médios ou altos índices de propensão à criminalidade. Então, foram propostas algumas políticas para a redução destes níveis, considerando diferentes categorias de municípios. Estas políticas visam diminuir os índices de criminalidade nos municípios paraibanos. Entretanto, observa-se que este não é um problema particular do Estado, mas compartilhado por todo o País, e que com o passar dos anos se agrava, pois recebe apenas soluções paliativas que não causam um grande impacto na sua resolução. Vale salientar ainda que algumas das soluções empregadas são de médio a longo prazo, portanto os programas precisam ser ininterruptos para que os resultados sejam alcançados. As discussões acerca do assunto devem ser feitas pelos responsáveis pela segurança em conjunto com a sociedade para que novas propostas e medidas sejam tomadas, visando o bem estar de quem sofre cotidianamente com esse problema.

Desta forma, o modelo aparece como uma alternativa positiva e flexível capaz de gerar soluções concretas e reais, de maneira que seja feita uma priorização dos locais que necessitam de maior atenção com relação aos critérios atribuídos a problemática, os quais o decisor poderá mudar de acordo com o estudo a ser realizado. Como resultado, espera-se o aumento da qualidade de vida da população, tendo em vista a maior confiança nas autoridades para cuidar do seu bem-estar e segurança. Além disso, apresenta um novo método para solução de problemas complexos no País.

Deve-se considerar também que os resultados expostos são provenientes de dados do último censo do IBGE e que há ausência de trabalhos deste tipo em municípios e Estados. Dessa forma, é necessário que os governos federal e estadual retomem seus estudos e pesquisas a respeito da renovação de tais elementos para que as informações possam estar sempre atualizadas. Vale salientar ainda que, de acordo com as últimas pesquisas realizadas pelo Instituto de Pesquisa Econômica Aplicada (IPEA), a Paraíba não se encontra entre os Estados mais violentos do País. Todavia, para avaliação dos fatores deste trabalho, é necessário a realização de uma avaliação de todos os Estados, classificando suas cidades a partir do modelo proposto, a fim de comparar as pesquisas, já que as realizadas pelo Instituto consistem em um ranqueamento dos Estados e municípios. 
Como sugestões para trabalhos futuros propõe-se utilizar outros métodos multicritério não compensatórios para a aplicação da sistemática proposta, como, por exemplo, os métodos da família ELECTRE; utilizar outros métodos para a atribuição dos pesos dos critérios por parte dos decisores, como, por exemplo, o swing weighting ou procedimento de Simo e; aplicar o modelo em outros Estados da Federação.

Agradecimentos. As autoras agradecem a Universidade Federal de Campina Grande pelo apoio ao longo do desenvolvimento desta pesquisa.

\section{Referências}

Adams-Curtis, L. E. e Forbes, G. B. College women's experiences of sexual coercion: A review of cultural, perpetrator, victim, and situational variables. Trauma, Violence, \& Abuse, v. 5, n. 2, p. 91-122, 2004.

Almeida, A. T. Processo de Decisão nas Organizações: Construindo modelos de decisão multicritério. São Paulo: Atlas, 2013.

Anjos, D. A., Vieira, M. A. e Almeida, F. M. Análise dos fatores determinantes da segurança pública nos municípios de Minas Gerais. Revista Brasileira de Estudos de Segurança Pública, v. 10, n. 2, p. 14-28, 2017.

Araújo, M. C. B. e Alencar, L. H. Integrated model for supplier selection and performance evaluation. South African Journal of Industrial Engineering, v. 26, n. 2, p. 41-55, 2015.

Araújo, M. C. B., Alencar, L. H. e Viana, J. C. Structuring a model for supplier selection. Management Research Review, v. 38, n. 11, p. 1213-1232, 2015.

Araújo, M. C. e Bezerra, C. E. Segurança pública: modelo multicritério para alocação de unidades policiais. In: Anais do XVII Latin-Iberian-American Conference on Operations Research (CLAIO), Lima, Peru, 2018.

Araz, C., Ozfirat, M. P. e Ozkarahan, I. An integrated multicriteria decision-making methodology for outsourcing management. Computers \& Operations Research, v. 34, n. 12, p. 3738-3756, 2007.

Araz, C. e Ozkarahan, I. Supplier evaluation and management system for strategic sourcing based on a new multicriteria sorting procedure. International Journal of Production Economics, v. 106, n. 2, p. 585-606, 2007.

Barité, M. Referenciales Teóricos Vigentes en el Área de Tratamiento Temático de la Información y su Expresión Metodológica. Porto Alegre: ABEBD, 1998.

Belsky, J. Child maltreatment: an ecological integration. American Psychologist, v. 35, n. 4, p. 320-335, 1980.

Bezerra Filho, J. G., Savioli, K. C., Gomes, E. M. e Araújo, I. S. G. (org.) Acidentes e Violência: uma abordagem interdisciplinar. Fortaleza: Eduece, 2015.

Brans, J. P., Mareschal, B. e Vincke, P. PROMETHEE: A new family of outranking methods in multicriteria analysis. Operational Research, v. 3, p. 477-490, 1984.

Cerqueira, D., Lima, R. S., Bueno, S., Neme, C., Ferreira, H., Coelho, D. et al. Atlas da Violencia. $\quad$ IPEA. 2018. Disponível em: 
www.ipea.gov.br/portal/images/stories/PDFs/relatorio_institucional/180604_atlas_da_violencia _2018.pdf. Acesso em: 11/03/2019.

Cerqueira, D. e Lobão, W. Determinantes da criminalidade: arcabouços teóricos e resultados empíricos. DADOS - Revista de Ciências Sociais, v. 47, n. 2, p. 233-269, 2004.

Doumpos, M. e Zopounidis, C. Multicriteria Decision Aid Classification Methods. Kluwer Academic Publishers, 2004.

Edleson, J. L. e Tolman, R. M. Intervention for Men who Batter: An ecological approach. Interpersonal violence: The practice series, Sage Publications, 1992.

Entorf, H. e Spengler, H. Socioeconomic and demographic factors of crime in Germany: evidence from panel data of the German states. International Review of Law and Economics, v. 20, n. 1, p. 75-106, 2000.

Fajnzylber, P., Lederman, D., Loayza, N., Reuter, P., Roman, J e Gaviria, A. Crime and victimization: an economic perspective. Economía, v. 1, n. 1, p. 219-302, 2000.

Figueiredo, C. J. J. Segurança pública: classificação das UDH's na cidade do Recife utilizando uma abordagem multicritério. 132 f. Dissertação (Mestrado em Engenharia de Produção) Universidade Federal do Pernambuco, Recife-PE, 2013.

Figueiredo, C. J. J. e Mota, C. M. M. A classification model to evaluate the security level in a city based on GIS-MCDA. Mathematical Problems in Engineering, v. 2016, ID 3534824, 2016.

Figueiredo, C. J. J., Mota, C. M. M., Pereira, D. V. S. e Gurgel, A. M. Exploração dos exemplos de referência no DRSA para um caso de segurança pública. In: Anais do XLVII Simpósio Brasileiro de Pesquisa Operacional, Porto de Galinhas-PE. SOBRAPO, 2015. p. 396-406.

Figueiredo, C. J. J., Pereira, D. V. S. e Mota, C. M. M. Avaliação de áreas em segurança pública: uma abordagem GIS-MCDA com sensoriamento remoto. In: Anais do XLIX Simpósio Brasileiro de Pesquisa Operacional, Blumenau-SC. SOBRAPO, 2017.

Fórum Brasileiro de Segurança Pública. Anuário Brasileiro de segurança pública. 2018. Disponível em: http://www.forumseguranca.org.br/wp-content/uploads/2019/03/AnuarioBrasileiro-de-Seguran\%C3\%A7a-P\%C3\%BAblica-2018.pdf. Acesso em: 04/03/2019.

Fulgencio, P. C. Glossário Vade Mecum: Administração pública, ciências contábeis, direito, economia, meio ambiente: 14.000 termos e definições. $1^{\text {a }}$ ed. Rio de Janeiro: Mauad X, 2007.

Gurgel, A. M. e Mota, C. M. M. A multicriteria prioritization model to support public safety planning. Pesquisa Operacional, v. 33, n. 2, p. 251-267, 2013.

Gurgel, A. M., Mota, C. M. M. e Aloise, D. J. Reducing violence: A proposal based on multicriteria SMARTS method. In: The IEEE International Conference on Industrial Engineering and Management, Singapura. IEEE, 2011. p. 76-80.

Gurgel, A. M., Mota, C. M. M. e Pereira, D. V. S. Gestão da segurança pública: um modelo de classificação multicritério combinado a sistemas de informações geográficas. In: Anais do XVI Congreso Latino Ibero-Americano de Investigación Operativa e XLIV Simpósio Brasileiro de Pesquisa Operacional, Rio de Janeiro. SOBRAPO, 2012. p. 475-481. 
Gurgel, A. M., Mota, C. M. M. e Pimenta, I. L. Public safety planning in Natal city: an application based on ELECTRE TRI model. In: Anais do 2014 IEEE International Conference on Systems, Man, and Cybernetics (SMC), San Diego-CA. 2014. p. 614-618.

IPEA - Instituto de Pesquisa Econômica Aplicada. Homicídios UF 1979 a 2017. 2017. Disponível em: http://www.ipea.gov.br/atlasviolencia/dados-series/17. Acesso em: 19/03/2019.

IPEA - Instituto de Pesquisa Econômica Aplicada. Estudo aponta cidades mais violentas da $P B$. Mais PB, 2019. Disponível em: https://www.maispb.com.br/401082/agreste-e-zona-damata-paraibana-possuem-cidades-mais-violentas.html. Acesso em: 15/05/2020.

L'apiccirella, N. O papel da educação na legitimação da violência simbólica. Revista Eletrônica de Ciências, v. 20, 2003.

Leedy, P. D. e Ormrod, J. E. Practical Research: planning and design. $7^{\text {a }}$ ed. New Jersey: Merrill Prentice-Hall, 2001.

Nunes, A. Política de segurança da Paraíba barra escalada da criminalidade. 2017. Disponível em: https://auniao.pb.gov.br/noticias/caderno_politicas/indices-de-violencia-na-pb-saoreduzidos-e-estado-evita-13-mil-homicidios\#. Acesso em: 09/06/2019.

Oliveira, C. M. G., Carmo, B. B. T. e Moreira, M. E. P. Alocação de postos de observação da polícia militar em uma cidade de médio porte: uma abordagem multicritério. Gestão da Produção, Operações e Sistemas, v. 10, n. 3, p. 139-158, 2015.

Panitz, M. A. Dicionário Técnico: português-inglês. $1^{\mathrm{a}}$ ed. Porto Alegre: EDIPUCRS, 2003.

Silva, A. L. O. Utilização do método multicritério PROMSORT na classificação de fornecedores para reparo de motores elétricos de indução em uma empresa pública de saneamento. 83 f. Dissertação (Mestrado em Engenharia de Produção) - Universidade Federal do Pernambuco, Recife-PE, 2012.

Silva, V. B. S., Morais, D. C. e Almeida, A. T. A multicriteria group decision model to support watershed committees in Brazil. Water Resources Management, v. 24, n. 14, p. 4075-4091, 2010.

Waiselfisz, J. J. Mapa da Violência 2012: Os Novos Padrões da Violência Homicida no Brasil. Instituto Sangari, 2012. Disponível em: www.mapadaviolencia.org.br/pdf2012/mapa2012_pb.pdf. Acesso em: 26/04/2019. 